\title{
Thomas erklärt gendergerechtes Schreiben
}

id "geschlechtergerechte/-sensible Sprache"

ist - im wahrsten Sinne des Wortes - in aller Munde.

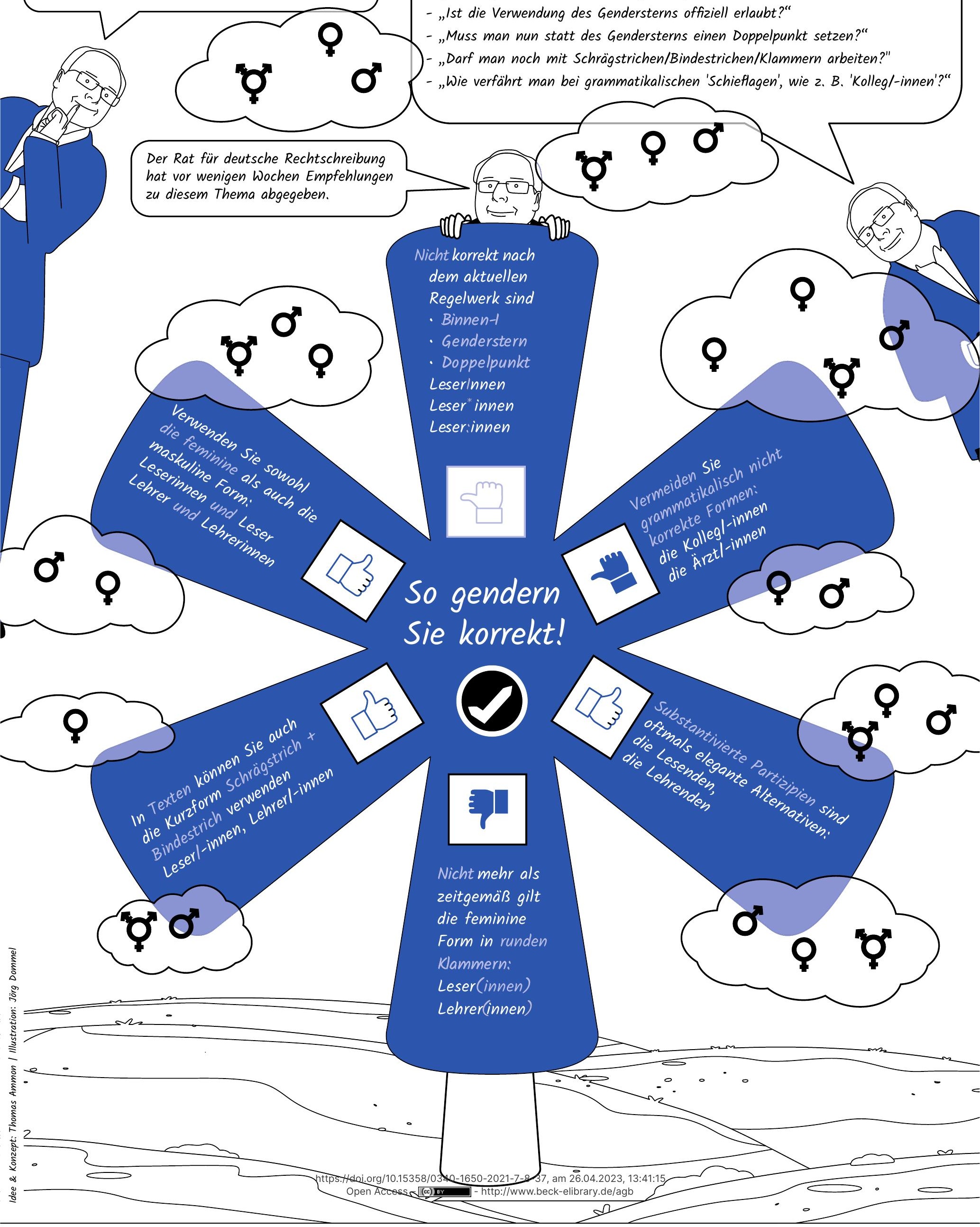

